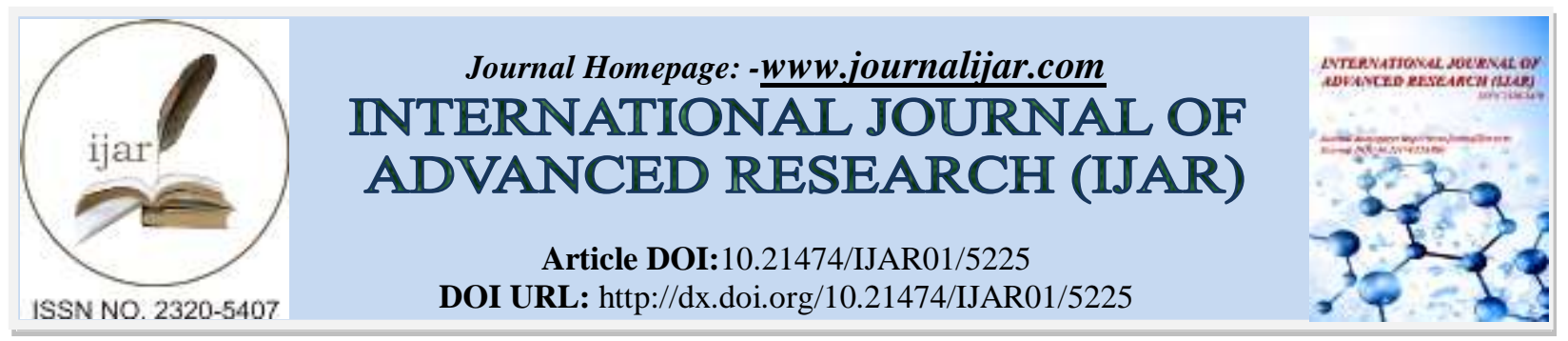

RESEARCH ARTICLE

\title{
A STUDY TO EVALUATE THE EFFECTIVENESS OF A SELF INSTRUCTIONAL MODULE ON KNOWLEDGE REGARDING PREVENTION OF ROAD TRAFFIC ACCIDENTS AMONG SCHOOL CHILDREN IN SELECTED SCHOOL AT KATHMANDU, NEPAL.
}

\begin{tabular}{|c|c|}
\hline \multicolumn{2}{|c|}{$\begin{array}{l}\text { Tara Ramtel. } \\
\text { Nagarik College of Health Sciences, Kathmandu, Nepal. }\end{array}$} \\
\hline Manuscript Info & Abstract \\
\hline $\begin{array}{l}\text { Manuscript History } \\
\text { Received: } 20 \text { June } 2017 \\
\text { Final Accepted: } 22 \text { July } 2017 \\
\text { Published: August } 2017 \\
\text { Keywords:- } \\
\text { Road Traffic Accidents; school; school } \\
\text { children; knowledge; prevention. }\end{array}$ & $\begin{array}{l}\text { Background of the study: Road Traffic Accidents are one of the } \\
\text { leading causes of death and disability among children and are mainly } \\
\text { due to ignorance and carelessness. So, children road safety education } \\
\text { and training is to be an important part for the children safety. } \\
\text { Objective: This study was undertaken to evaluate the effectiveness of } \\
\text { Self Instructional Module (SIM) on Knowledge of school Children } \\
\text { regarding Prevention of Road Traffic Accidents. Method: In this pre- } \\
\text { experimental study design was used. Total } 100 \text { children were selected } \\
\text { by convenience sampling. A structured knowledge questionnaire was } \\
\text { used. Subsequently, the data was analyzed by using descriptive and } \\
\text { inferential statistics. Result: The mean pre-test knowledge score was } \\
34.2 \% \text { (SD of } \pm 20.8 \text { ) whereas the mean post-test knowledge score was } \\
85.3 \% \text { (SD of } \pm 11.1 \text { ). A significant difference was found between mean } \\
\text { pre-test and post-test knowledge scores ('t' }=21.75 \text {, p< } 0.05 \text { ). A } \\
\text { significant association was found between mother's educational status, } \\
\text { father's educational status, types of family, distance from home to } \\
\text { school, mode of travel, types of accident met, exposure to information } \\
\text { on prevention of Road Traffic Accidents and the source of information } \\
\text { ( } \chi^{2}=14.83,9.80,7.50,12.47,6.89,5.66,25.97,27.88 \text { at p< } 0.05 \text { ). } \\
\text { Conclusion: The samples had inadequate knowledge regarding all the } \\
\text { aspects of Road Traffic Accidents. The study finding indicates that Self } \\
\text { Instructional Module was effective in enhancing the knowledge of } \\
\text { school children regarding the prevention of Road Traffic Accidents. }\end{array}$ \\
\hline
\end{tabular}

Copy Right, IJAR, 2017,. All rights reserved.

\section{Introduction:-}

Children are the biggest assets of a nation. They represent country's future. Children, being less aware of danger, are one of the most vulnerable groups prone for accidents. As the country develops, traffic has become a burning problem. Road Traffic Accidents are one of the major incidences of injury and death in children of school age. Accidents are often due to ignorance, carelessness, thoughtlessness and over confidence [1]. The consequence of accidents seriously affects the growth and health of children and interferes in their study and future. So it is important to protect the life of the children and to provide safer environment. According to the WHO, Road Traffic Accidents (RTA) is the second most important cause of death for 5 to 29 year olds. Every hour, 40 people under the age of 25 die in road accidents around the globe [2]. 
Accidents are one of the five leading causes of death in industrialized and developing countries. Injuries arising from accidents are an increasing public health problem. Yearly, $10 \%$ of children suffer an accident for which it is necessary to contact the health services. As a public health problem, injuries cannot and indeed must not, be neglected any longer [3]. UNICEF and WHO (2005) issued an article on child and adolescent injury prevention - a global call to action stated that child injuries are not necessarily purely "accidental" as random events; to a degree they are predictable and therefore largely preventable. Our children and young adults are among the most vulnerable. Road traffic crashes are not 'accidents'. We need to challenge the notion that they are unavoidable and make room for a pro-active, preventive approach [4].

Road accidents accounted for 55\% of all accidental death in children and in almost all of these, the unsafe behavior of child was considered to be at fault. These road accident deaths occur in healthy children who might have been expected to have had productive lives and cause immeasurable distress and guilt to the parents and other parties involved. So the prevention of accidents in children is being increasingly recognized as an important public health issue [5].

Pedestrian road traffic injuries among children and adolescents are most important cause of death and disability. The greater vulnerability of children compared to adults has been attributed to their developmental and behaviour limitations in complex traffic situations. Pedestrians aged 10 years us below are particularly vulnerable because of their small physical situations, both cognitive attention focus, interpreting signs as perceptual locating sounds, judging speed, peripheral vision Studies shows that showed that children ages 5-9 years make a greater number of unsafe road crossing than the older children. Children under the age of 10 years don't have the ability to cross the roads without adults help; children's capacities are poorer than adults to perform struck crossing tasks, particularly scanning the environment as a whole. The more the complexity of the traffic environment, the more difficult the task and therefore the vulnerability of children 0-10 years called be attributed to the fact that they may not have attained the maturity for pedestrian road use. WHO gender differences in childhood traffic injuries have also been identified with boys being more likely to be injured than girls [6].

The huge number of injury and death due to road traffic accident reveals the story of global crisis of road safety. Road collisions are the second leading cause of death for people between the ages of 5 and 29 and third leading cause for people between 30 and 44 . With the number of vehicles rapidly rising in developing countries, this epidemic is quickly worsening in low and middle income countries and is on its way to becoming the third leading cause of death and disabilities by the year 2020. The loss in road traffic accidents enormous in economy and health related issues [6]. Every day around the world, almost 16000 people die from injuries. For every person that dies, several thousands more are injured, many of them with permanent squeal of injuries. Injuries occur in all regions and countries, and affect people of all ages and income groups. The magnitude of the problem however varies considerably by age, sex, region and income group. An estimated 1.2 million people lose their lives in road traffic crashes every year, and another 20 to 50 million are injured. This problem of road traffic crashes and resulting injuries and fatalities is however more acute in a developing country. The World report on road traffic injury prevention calls for governments to make road safety a political priority, and highlights recommendations with regard to policy, legislation and enforcement, and development of institutional capacity to improve road safety. It has been experienced all over the world that the countries which are undergoing increasing and rapid motorization face proportionately higher number of road accidents.

At the earliest stages of road safety development, little or no safety awareness may exist and efforts will first need to be made to enhance the awareness of key decision-makers to the scale and nature of the problem and the actions that is necessary to alleviate the situation. Awareness about various road safety rules and road signs, first aid methods and techniques that enhance practices related to the prevention, the preparedness and the immediate response to health emergencies should be provided to road safety; this increases the social responsibility of the society and strengthens humanitarian values [7].

Fatal road accidents are a major cause of childhood mortality up to 16 years of age. Children are themselves at fault in majority of cases. To prevent these early childhood death, children should be educated about traffic rules and safety precautions. The main aim of road safety is to convey information to road users so as to enhance their knowledge about road safety issues, influences their behaviour on the road safety and to prepare them for new safety measures [8]. 


\section{Methods:-}

The research design used in the study was pre-experimental one group pre test and post test design. The setting of the study was at Grammar Boarding School at Kathmandu. The target population for the study comprises of class 5 \& 6 students from selected school.

The study sample size consists of 100 school children those who fulfill the inclusion criteria. In order to assess the knowledge of school children regarding prevention of Road Traffic Accidents, a convenience sampling technique was used.

A self instructional module and a structured questionnaire were prepared. The tool used for the study comprised of a demographic performa and a structured knowledge regarding Prevention of Road Traffic Accidents. The questions are phrased in multiple choice forms with four options, three as distracters and one as correct response. The correct response is given a score of one and incorrect response a zero score. Thus the maximum possible score is 30 .

The resulting knowledge score ranged as,

\begin{tabular}{|c|c|c|}
\hline Knowledge score & No. of items & Percentage \\
\hline Adequate knowledge & $23-30$ & $>75 \%$ \\
\hline Moderate knowledge & $16-22$ & $51-75 \%$ \\
\hline Inadequate knowledge & $1-15$ & $<50 \%$ \\
\hline
\end{tabular}

Formal permission was obtained from the concerned Principal of Grammar Boarding School of Kathmandu. Samples were selected according to the laid down inclusion criteria. Confidentiality was assured. Written consents were obtained.

A questionnaire was administered to each of the 100 students. Doubts were clarified in between. On an average it took approximately 30 minutes to complete the test. Then SIM was provided at the completion of the study with a brief explanation about its objectives and contents. On the day $10^{\text {th }}$, post test was conducted for all respondents.

\section{Development of the Self Instructional Module (SIM):-}

The SIM on knowledge regarding Prevention of Road Traffic Accidentswas prepared after reviewing the research and non-research literature and seeking opinion of the subject guide.

The steps followed in the development of SIM are as follows:

1. Review of literature.

2. Organization of the content of SIM.

3. General information regarding road traffic accidents.

4. Definition, causes,

5. Prevention road traffic accidents.

6. Rules to enhance road safety.

7. Assessment of the content validity of SIM.

8. Preparation of final draft of the SIM.

9. Editing the module.

The obtained data were analyzed using both descriptive and inferential statistics on the basis of the objective and hypothesis of the study. Demographic data containing sample personal characteristics were analyzed by using frequencies and percentage. The knowledge score before and after the administration of the self instructional module will be calculated by using mean, standard deviation and ' $t$ ' test. The level of significance was at $\leq 0.05$ level. The effect of SIM was analyzed by paired ' $t$ ' test. Association of socio-demographic variables with pre test knowledge score was found by using chi square test.

\section{Results:-}

The data was collected from the respondents before and after the administration of the Self Instructional Module. The collected information was organized, tabulated, analyzed and interpreted by using descriptive and inferential statistical methods.

Classification of Respondents by Personal Characteristics:-

The result indicates that, $36.7 \%$ of the respondents were in the age group of $9-10$ years followed by $33.3 \%$ in the age 
group of $10-11$ years and $30 \%$ in the age group of $11-12$ years. Out of the 100 respondents, $67 \%$ were males and $33 \%$ were females. All the respondents were Hindus.

With regard to the distance from home to school, $43.3 \%$ of the respondents were residing less than $2 \mathrm{~km}$ from the school, $26.7 \%$ of the respondents were residing between $2 \mathrm{~km}$ to $4 \mathrm{~km}$ and $30 \%$ of the respondents were residing above $4 \mathrm{~km}$. With regard to the mode of travel to school, $56.7 \%$ of the respondents used to travel by school bus, $8.3 \%$ of the respondents used bicycle to reach to the school and $35 \%$ of the respondents depends on other mode of transportation. Majority of the respondents, $46.7 \%$ likes outdoor games to spend their leisure time whereas $35 \%$ likes indoor games and $18.3 \%$ spend their leisure time in other ways.

With regard to mother's educational status, $31.7 \%$ were graduates, $31.7 \%$ were educated up to Pre-University College and the remaining 36.6\% were other qualifications. Regarding mother's occupational status, $51.7 \%$ were unemployed whereas $48.3 \%$ were employed. With regard to father's educational status, $16.7 \%$ were graduates, $36.7 \%$ were educated up to Pre-University College and 46.6\%) were having other qualifications. All the fathers' were employed.

\section{Classification of Respondents by Related Characteristics:-}

With regard to ever met with any minor or major accident by the respondents, $100 \%$ respondents agreed that they met with minor or major accidents. With regard to type of minor or major accident met, 53.3\% of the respondents had fall from bicycle while riding and $46.7 \%$ agreed to meet with other type of minor or major accidents.

With regard to information on prevention of Road Traffic Accidents, 78.3\% of the respondents had not received any information regarding Road Traffic Accidents whereas 18.4\% had received information on prevention of RTA from parents and $3.3 \%$ had received information from Television.

Overall and Aspect-wise Pre-test Knowledge level on Prevention of Road Traffic Accidents:-

Table 1:-Classification of Respondents on Overall Pre-test Knowledge level on Prevention of Road Traffic Accidents.

\begin{tabular}{|l|c|c|c|}
\hline Knowledge Level & Category & Respondents \\
\cline { 2 - 4 } & & Number & Percent \\
\hline Inadequate & $\leq 50 \%$ Score & 33 & 67.0 \\
\hline Moderate & $51-75 \%$ Score & 0 & 0.0 \\
\hline Adequate & $>75 \%$ Score & $\mathbf{1 0 0}$ & $\mathbf{1 0 0 . 0}$ \\
\hline Total & & 0 & 0 \\
\hline
\end{tabular}

The data depicted in the above table shows the classification of school children with regard to their pre-test knowledge level on prevention of Road Traffic Accidents. It was observed that, majority of the samples $67 \%$ had inadequate knowledge ( $\leq 50 \%$ scores) and 33\% had moderately adequate knowledge (51-75\% scores). It was alarming to observe that none of the respondents had adequate knowledge (>75\% scores) regarding prevention of Road Traffic Accidents in the pre-test.

The aspect-wise Pre-test Mean Knowledge scores on Prevention of RTA among School children was that the participants had highest mean score, $40.7 \%$ in the area of rules to enhance the Road Safety, 35.4\% in the area of general information regarding RTA, 32.4\% was observed regarding prevention of RTA and a score of $29.7 \%$ regarding causes of RTA. Mean percentage aspect-wise pre-test knowledge score showed that the respondents had inadequate knowledge in the selected aspects of Road Traffic Accidents.

Overall and Aspect-wise Post-test Knowledge scores on Prevention of Road Traffic Accidents:Table 2:- Classification of Respondents on Post-test Knowledge level on Prevention of Road Traffic Accidents

\begin{tabular}{|l|c|c|c|}
\hline \multirow{2}{*}{ Knowledge Level } & Category & Respondents & \multicolumn{2}{|c}{ Percent } \\
\cline { 3 - 4 } & & Number & 0.0 \\
\hline Inadequate & $\leq 50 \%$ Score & 0 & 21.0 \\
\hline Moderate & $51-75 \%$ Score & 79 & 79.0 \\
\hline Adequate & $>75 \%$ Score & $\mathbf{1 0 0}$ & $\mathbf{1 0 0 . 0}$ \\
\hline Total & &
\end{tabular}

Data presented in the above table shows the overall mean of the post-test knowledge scores of school children 
regarding prevention of Road Traffic Accidents. The majority of the samples 79\% had gained adequate knowledge and $21 \%$ had gained moderately adequate knowledge regarding the selected aspects of Road Traffic Accidents.

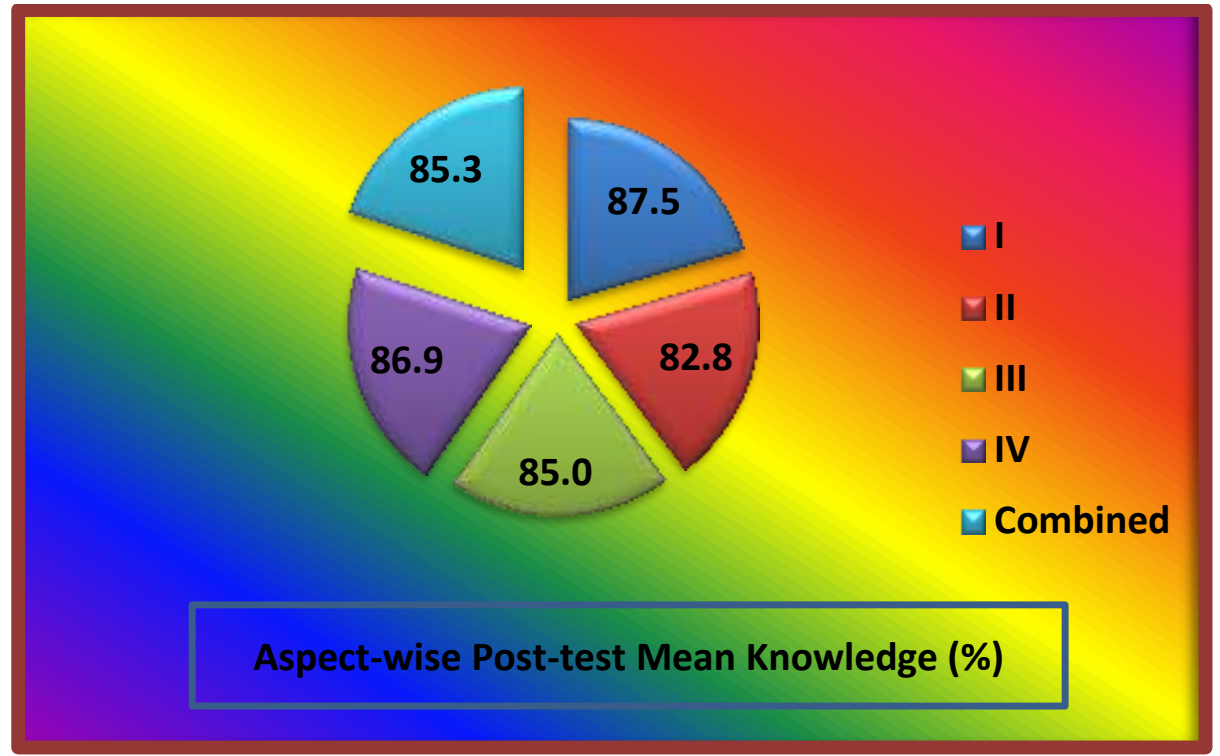

Figure 1:-Aspect-wise Post-test Mean Knowledge scores on Prevention of Road Traffic Accidents among School Children

As shows in the figure 1, the participants had highest mean score $87.5 \%$ in the area of general information regarding Road Traffic Accidents, $86.9 \%$ regarding rules to enhance the road safety, $85.0 \%$ in the area of prevention of RTA and $82.8 \%$ in the area of causes of RTA. Mean percentage aspect-wise post-test knowledge showed that the respondents had adequate knowledge in the selected aspects of Road Traffic Accidents.

Comparison of Mean Pre-test and Post-test Knowledge scores of School Children to Evaluate the Effectiveness of Self-Instructional Module on Prevention of Road Traffic Accidents:-

To evaluate the effectiveness of the Self-Instructional Module on prevention of Road Traffic Accidents, a null hypothesis $\left(\mathrm{H}_{01}\right)$ was formed that is, there is no significant difference between the mean pre-test and post-test knowledge scores of school children regarding prevention of Road Traffic Accidents.

Table 3:-Comparison of Overall Pre-test and Post-test Mean Knowledge on Prevention of Road Traffic Accidents among School Children.

\begin{tabular}{|l|c|c|c|c|c|c|}
\hline \multicolumn{1}{|c|}{ Aspects } & $\begin{array}{c}\text { Max. } \\
\text { Score }\end{array}$ & \multicolumn{4}{|c|}{ Respondents Knowledge } & \multirow{2}{*}{ Paired- 't' Test } \\
\hline & & Mean & SD & Mean (\%) & SD (\%) & \multirow{2}{*}{$21.75^{*}$} \\
\hline Pre-test & 30 & 10.27 & 6.2 & 34.2 & 20.8 & \\
\hline Post-test & 30 & 25.60 & 3.3 & 85.3 & 11.1 & \\
\hline Enhancement & 30 & 15.33 & 5.5 & 51.1 & 18.2 & \\
\hline
\end{tabular}

The data depicted in the above table showed that the mean post-test knowledge scores (85.3\%) was significantly higher than the mean pre-test knowledge scores $(34.2 \%)$ at $0.05 \%$ level of significance.

Association of Mean Pre-test Knowledge Scores of School Children regarding Prevention of Road Traffic Accidents and their selected Socio-demographic Variables:-

To determine the association between the selected socio-demographic variables and the pre-test knowledge of school children regarding the prevention of Road Traffic Accidents, a null hypothesis $\left(\mathrm{H}_{02}\right)$ was developed that is, there is no significant association between pre-test knowledge scores of school children regarding the prevention of Road Traffic Accidents and the selected socio-demographic variables such as age, religion, educational status of 
parents, occupational status of parents, number of siblings, type of family, distance from home to school, mode of travel to school, leisure time activity, type of accident ever met by the participants, exposure to prior information on prevention of Road Traffic Accidents and source of information on prevention of Road Traffic Accidents.

Regarding the mode of travel to school, the obtained $\chi^{2}$ value (6.89) is found to be more than the table value (5.99, 2d.f) at 0.05 level of significance. Therefore the null hypothesis is rejected and the research hypothesis is accepted. It means that there is a significant association between the mode of travel to school and the mean pre-test knowledge level of the school children regarding the prevention of Road Traffic Accidents.

Regarding the type of accident ever met by the respondents, the obtained $\chi^{2}$ value (5.66) is found to be more than the table value $(3.84,1$ d.f) at 0.05 level of significance. Therefore the null hypothesis is rejected and the research hypothesis is accepted. It means that there is a significant association between the type of accident ever met and the mean pre-test knowledge level of the school children regarding the prevention of Road Traffic Accidents.

With regard to prior exposure to information regarding prevention of Road Traffic Accidents, the obtained $\chi^{2}$ value (25.97) is found to be more than the table value $(3.84$, 1d.f) at 0.05 level of significance. Therefore the null hypothesis is rejected and the research hypothesis is accepted. Therefore, there is a significant association between prior exposure to information regarding prevention of Road Traffic Accidents and the mean pre-test knowledge level of the school children regarding the prevention of Road Traffic Accidents.

Regarding the source of information on prevention of Road Traffic Accidents, the obtained $\chi^{2}$ value (27.88) is found to be more than the table value $(5.99,2$ d.f) at 0.05 level of significance. Therefore the null hypothesis is rejected and the research hypothesis is accepted. Hence, there is a significant association between the source of information regarding prevention of Road Traffic Accidents and the mean pre-test.

\section{Discussion:-}

To discuss the significant findings of data analysis in accordance with the objectives and stated hypothesis of the present study, it was observed that the mean pre-test knowledge score of school children regarding the prevention of Road Traffic Accidents was inadequate. Study shows that, majority of the samples $66.7 \%$ had inadequate knowledge ( $\leq 50 \%$ scores) and $33.3 \%$ had moderately adequate knowledge (51-75\% scores) regarding prevention of Road Traffic Accidents. It was alarming to observe that none of the respondents had adequate knowledge ( $>75 \%$ scores) regarding prevention of Road Traffic Accidents.

The finding is supported by the other studies conducted on the effectiveness of education on knowledge, attitude and practice on road safety among middle school students study concluded that the program on road safety education significantly improved the relative knowledge for middle school student and it exerted positive effects in road safety attitude although no significant effect was found in the improvement on their behaviour. Studies recommend that education on road safety should be carried out in the early stage of childhood with newer and more effective intervention approaches [9].

It was observed in the mean post-test knowledge score that $65 \%$ of the samples had gained adequate knowledge and $35 \%$ had gained moderately adequate knowledge regarding the prevention of Road Traffic Accidents after the administration of Self-Instructional Module. The result showed that after the administration of SelfInstructional Module all school children had gained moderately adequate to adequate knowledge regarding prevention of Road Traffic Accidents.

The comparison of overall pre-test and post-test mean knowledge scores of children regarding prevention of Road Traffic Accidents showed an enhancement mean of 15.33 with S.D of \pm 5.5. The observed mean percentage enhancement score is $51.1 \%$ with S.D of \pm 18.2 . When paired- ' $t$ ' test was done the obtained ' $t$ ' value is $21.75[\mathrm{t}(0.05,59 \mathrm{~d} . \mathrm{f})=1.96]$. From this, it can be inferred that Self Instructional Module was effective in enhancing the knowledge of children.

Association was sought between the mean pre-test knowledge scores and their selected socio-demographic variables such as age, religion, educational status, occupational status, type of family, distance from home to school, mode of travel, type of accident met, exposure to information on prevention of Road Traffic Accidents and the source of information. 
Among these, a significant association was found between mother's educational status $(\chi 2=14.83)$, father's educational status $(\chi 2=9.80)$, type of family $(\chi 2=7.50)$, Distance from home to school $(\chi 2=12.47)$, mode of travel $(\chi 2=6.89)$, accident met $(\chi 2=5.66)$, exposure to information on Road Traffic Accidents $(\chi 2=25.97)$ and the source of information $(\chi 2=27.88)$. Other socio-demographic variables such as age, religion, occupation of mother, number of siblings did not show any significant association with pre-test knowledge.

\section{Conclusion:-}

Accidents are increasingly globally as a public epidemicamong that incidence of road traffic accident is ever rising. Road traffic injuries are major cause of death and disability globally and the children are the most vulnerable group. The factors include man, the vehicle and the road. Areview of the etiological factors presented it is evident that road safety education is unavoidable. A large proportion Children behaved more safely following training, indicating very brief training can produce at least short-term improvements in pedestrian behaviors.

Road accidents account for a third of accidental deaths among 0-14 year olds and over half of accidental deaths for 5-14 year olds. They are so numerous that they can often swamp the figures from other accidents and make it difficult to discern which other accident types have the largest impact on children and young people. Childhood is referred to a formative years of life, because it is the stage during which most development occurs hence skills are acquired. School is the unique settings for the early detection and prevention of Road Accidents. It is very urgent and essential today to implement the Road Safety Education at school level to help the children to excel their future.

Young children should be trained the basic concept of error avoidant road user behavior so that they can perceive themselves as having a personal responsibility for maintaining safety.

\section{Acknowledgements:-}

The author would like to thank Ms. Manodari Thapa Ex-registrar of Nepal Nursing Council for her valuable advice and all the research committee members of Nagarik College of Health Sciences for their cooperation and support during study.

\section{References:-}

1. Albert L. Should the Health Educated be Regarded as Professional, Promotion and Education Paris; 2000;9(1):3-6.

2. Manciaux M, Romer CJ, eds. Accidents in childhood and adolescence. The Role of Research, Geneva, World Health Organization and Institute National de la Santé et de la RechercheMédicale INSERM,1991 1-72).

3. Marcusson H, Oehmisch W. Accident Mortality in Childhood in Selected Countries of Different Continents, 1950- 1971. World Health Statistics Report, 1977, 30 (1):57-92.

4. UNICEF, WHO Child and Adolescent Injury Prevention - A Global Call to Action. Department of Injury and Violence Prevention, (2005); 1-14.

5. Bannon MJ, Carter YH, Mason KT. Causes of Fatal Childhood Accidents in North Staffordshire. Emergency Medicine Journal. 1992; 9:357-366.

6. Koushki. PA, Bnotan. MA, N, Impact of safety belt use on road accident injury and injury type in Kuwait, Accident annual preview. 2003. Mar.(2) P. 41- 237.

7. Lamb R, Joshi MS, Carter W, Cowburn G, Matthews A, Children's acquisition and retention of safety skills: the life skills program Inj Prev. 2006 Jun;12(3):161-5.

8. Harnam Singh, A. D. Aggarwal. Fatal Road Traffic Accidents among Young Children. Journal of Indian Academy of Forensic Medicine. 2011, 32(4).

9. C K Priyanka Raj, ShibSekharDatta, Jayanthi V, Zile Singh, Senthilvel V, Study of Knowledge and Behavioural Patterns with regard to Road Safety among High School Children. Indian Journal of Medical Specialities. 2011.

10. Germeni E, Lionis C, Kalampoki V, Davou B, Belechri M, Petridou E. Center for Research and Prevention of Injuries (CEREPRI), Department of Hygiene, Epidemiology and Medical Statistics, Athens University Medical School, Health Educational Research. 2010 Oct;25(5):865-76 